\title{
Improvement of Power System Transient Stability Using Fuzzy Controlled Shunt Facts Device
}

\author{
B. Gopal Reddy ${ }^{1}$, Kamaldeep Sharma ${ }^{2}$ \\ ${ }^{1}$ Department of Electrical and Electronic Engineering, Lovely Professional University, Jalandhar, Punjab, India \\ ${ }^{2}$ Department of Electrical and Electronic Engineering, Lovely Professional University, Jalandhar, Punjab, India
}

\begin{abstract}
In this modern world, the electrical power consumption is vast and its power system is complex and faces many challenges due to growing demand and construction of new lines. Transient stability is one of the main system insecurity when large disturbances occur. Here at first conventional shunt facts devices Static VAR Compensator (SVC), Static Synchronous Compensator (STATCOM)are used as an additional supplementary controller to enhance transient stability. This paper proposes a Fuzzy Logic Controller to determine th signal to control STATCOM for damping the rotor angle oscillations of the machine to improve system stability. This controller is tested on 2-machine 3-bus system. Here the parameters like deviation of rotor angle, terminal voltages of buses are observed. The results are compared to conventional SVC and STATCOM to Fuzzy controlled STATCOM to prove that Fuzzy controlled STATCOM gives better results. The MATLAB/SIMULINK software is used to verify the model designed.
\end{abstract}

Keywords: STATCOM, SVC, FACTS, VSC.

\section{Introduction}

In transmission system of existing power systems the stress due to growing the load demand and restrictions placed by new formation lines is increasing and main consequence of such a system is the stability losing after occurrence of the disturbances in the transmission system. In order to stabilize the system the Flexible AC Transmission System (FACTS) devices are very effective in transmission network. These devices are externally attached to the network transmission line with much effort to change the line connections and they control the real and reactive power flow in the line. The FACTS shunt devices in this network system are Static VAR Compensator (SVC) and Static Synchronous Compensator (STATCOM) which are employed with newest technology of power electronic devices in power transmission systems in order to control the transient stability of the system. The STATCOM is used to regulate voltage at its terminal which is connected to the transmission line by controlling the amount of reactive power injected into or absorbed from power system. When the voltage in system is running low due to some disturbance this device injects the reactive and vice-versa to compensate the real power flow in the transmission line.

At the present time, transient stability due to large disturbances is the most serious problem which destabilizes the entire power system. The transient stability problem is occurred due to large disturbances which takes place on the transmission lines. The fault for this instability is three phase to ground fault where the normal Power System Stabilizer (PSS) becomes useless without an additional controlling device that is FACTS devices. These devices are connected in the transmission line to control the reactive power in the system by controlling current or voltage in the line. Further to improve the stability of the system with nonlinear characteristics a Fuzzy Logic is used in the FACTS devices which are more advanced logic method to control the nonlinear systems. The application and design processes of controller is described in the further chapter.
In this paper, FACTS devices which are shunt like Static VAR Compensator (SVC), Static Synchronous Compensator (STATCOM) are connected in the transmission line of the power system as these devices have the capability to enhance both dynamic performance steady state stability and of the system. Here voltage source converter is present which produces the controllable voltage when voltage difference across the reactance produces reactive power exchange between the transmission line and STATCOM.

\section{SVC Operation}

The Static VAR Compensator is used to provide fast acting reactive power in transmission lines with high voltages, it is a set which comprises of electronic devices. SVCs are part of FACTS device family and used to regulate voltage, harmonics, power factor and stability in system. SVC is called a static device as it does not have any revolving parts like in synchronous condensers. Before the invention of SVC device the power factor compensation is done by switched capacitor banks or rotating machines like synchronous condensers. It is a device which automatically matches the impedance and brings the system nearer to unity power factor. SVCs are connected to transmission line in a power system to regulate the voltage transmitted in the transmission line and it is also connected nearer to large industrial loads to improve the power quality of the industries. The model of $\mathrm{SVC}$ is given in fig 1 . 
International Journal of Science and Research (IJSR)

ISSN (Online): 2319-7064

Index Copernicus Value (2013): 6.14 | Impact Factor (2015): 6.391

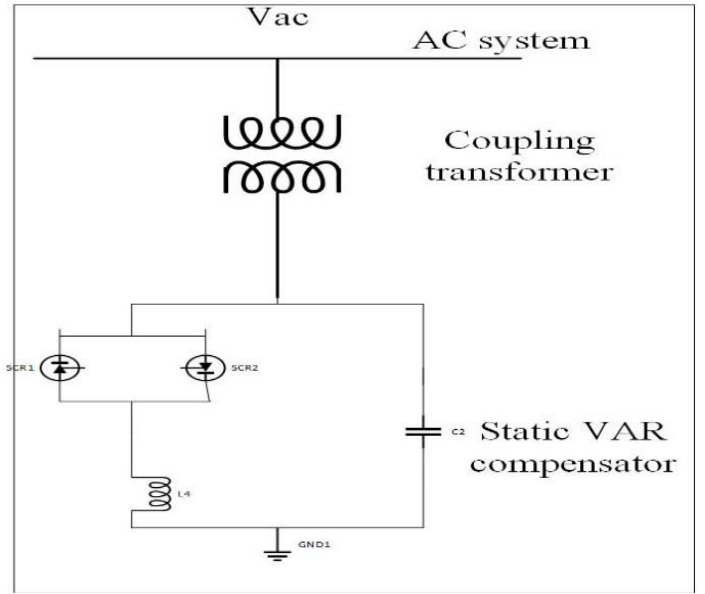

Figure 1: SVC MATLAB model

For transmission applications the system which has grid connection SVC is used to regulate the voltage in the grid. If the reactive load is leading in the power system the SVC device will use the TCRs to consume the voltage across the reactors from the system while lowering the voltage of the system. If the reactive load is lagging in power system the capacitor banks in SVC device will automatically switches in to provide the higher voltage to the system. Due to TCR and capacitor bank the result is lagging or leading power which is continuously variable.

For industrial applications, the SVCs are connected near large and rapidly changing loads like arc furnaces where the smooth's the flickering voltage.

In steady state analysis the characteristics of the SVC are modeled for its steady state controlling studies. For transient stability studies where high fault conditions and low frequency is of great interest, here the SVC is represented in a steady state for first approximation. But model the SVC for damping contribution it is needed to consider the dynamic characteristics of SVC controller. The output provided by the SVC controller device is the susceptance $B_{S V C}$ which is time varying parameter. If this is included in the network the admittance matrix which is a time varying is given which may be problematic. For SVC current calculation the equivalent is updated at every time step taken. The firing angle alpha is provided to TCR are calculated by distribution unit and it also provides the switching pulse for the thyristorsusceptance control. The $\mathrm{Vm}$ voltage is provided by the measuring system. The Vref and Vm voltages are used to determine the susceptance B of the SVC by using the voltage regulator. The control model of SVC is given in fig 2 .

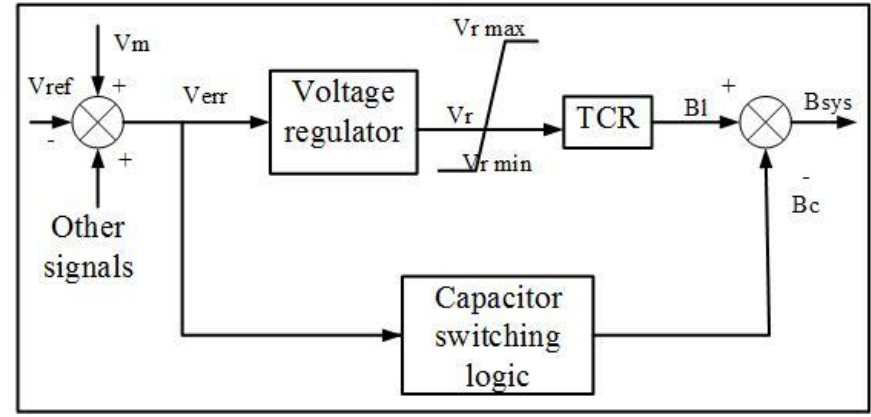

Figure 2: SVC Control model

\section{STATCOM Operation}

STATCOM is a shunt connected device which uses power electronic devices like IGBT, GTO to control the flow of power and in order to improve the transient stability in an electric power systems. The STATCOM uses GTO or IGBT which are force commutated electronic devices. This device is given the word static because it does not have any revolving parts like in synchronous generator. STATCOM operates faster compared to the rotating devices like synchronous generators. This device is a static synchronous generator which is operated as a shunt connected SVC whose inductive or capacitive output current is controlled independent of the system voltage in A.C systems. The STATCOM is mainly based on current sourced or voltage sourced converter.

The STATCOM concept was proposed in 1976 by Gyugyi. In VSC based STATCOM dc voltage has only one polarity, and in order to reverse the power the dc current polarity is reversed first while in CSC based STATCOM the dc current also has one polarity and to reverse the power the dc voltage polarity is reversed first. The CSC based STATCOM requires the power electronic devices which has bidirectional voltage capability and to achieve this property a diode is connected in series with switch which indirectly increases the cost of the system so it is more costlier then VSC based STATCOM. This VSC can operate in larger power applications with larger efficiency. Due to above reasons the VSC is mainly preferred than the CSC based STATCOM. The technologies preferred differs upon the change in power rating of STATCOM.

For lesser power ratings IGBT is used as for higher power rating GTO based power electronic devices are used in STATCOM. STATCOM is designed using a voltage source converter, coupling transformer and a dc energy device as a storage unit. This storage device is used to exchange reactive power with transmission line. If a dc storage battery or voltage source is used in place of dc capacitor the controller can exchange both reactive and real power with the system through transmission line and extending its operation region from two quadrants to four quadrants. Fig 3 shows STATCOM model.

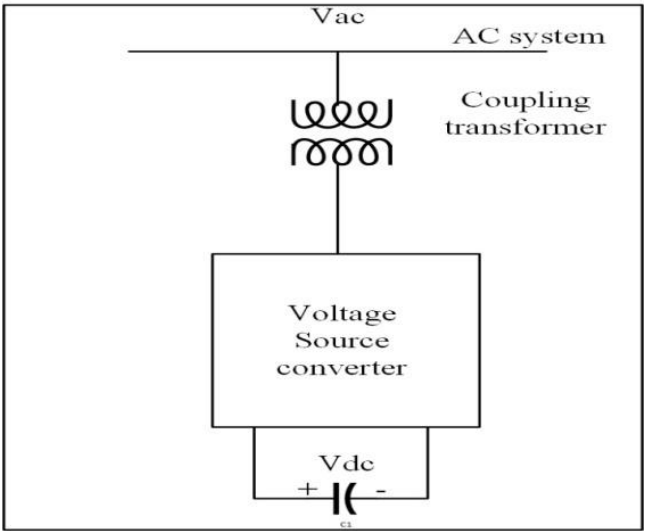

Figure 3: STATCOM MATLAB model

During the voltage regulation mode of the STATCOM the $\mathrm{V}-\mathrm{I}$ characteristics are shown and its equation is as follows: 


\section{International Journal of Science and Research (IJSR) \\ ISSN (Online): 2319-7064}

Index Copernicus Value (2013): 6.14 | Impact Factor (2015): 6.391

\section{$\mathrm{V}=\mathrm{V}_{\text {ref }}+\mathrm{X}_{\mathrm{s}} \mathrm{I}$}

Where V is Positive sequence voltage, I is Reactive current $\left(\mathrm{pu} / \mathrm{P}_{\text {norm }}\right)(\mathrm{I}>0$ indicates an inductive current and $\mathrm{I}<0$ indicates capacitive current), $\mathrm{Xs}$ is Slope (usually between $1 \%$ and $5 \%), \mathrm{P}_{\text {norm }}$ is Converter rating in MVA. The real power absorbed or generated by STATCOM depends upon the capacitor size which stores the charge or discharge it accordingly. Comparison to SVC, SATCOM provides various advantages for reactive power control. In this paper a mamdani based fuzzy logic controller is designed and the inputs provided to it are error voltage in the system and it's derivate of provided error voltage.

The STATCOM is operated on three modes. In No load mode of operation, in this mode of operation the both voltages across the converter and ac system is in phase and no exchange of reactive power takes place. In the capacitive mode of operation, in this mode of operation the ac current leads the voltages and the reactive power is generated in converter and the flow of this power happens from converter via coupling transformer to the ac system. In the inductive load of operation, in this mode of operation the ac current lags to the voltages and the reactive power is absorbed by the converter from the ac system via the coupling transformer.

The control block of the STATCOM is given in fig 4. The AC positive sequence currents and voltages of $\mathrm{d}$ and $\mathrm{q}$ components are measured by the measurement blocks. In outer loop it consists of DC regulator and $\mathrm{AC}$ regulator. The $\mathrm{AC}$ regulator provides the current Iqref for current regulator and DC regulator is used to provide the current Idref which is given as input to the current regulator.

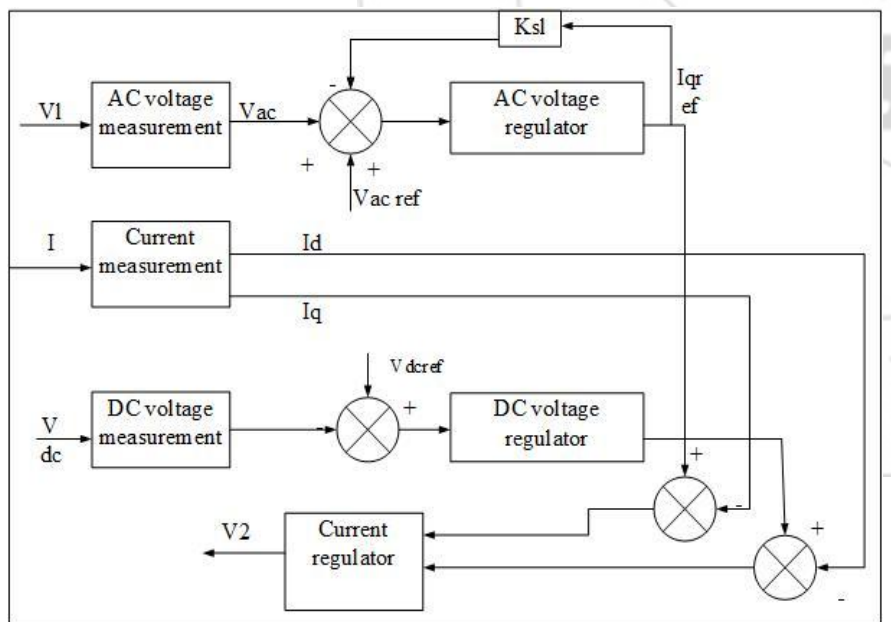

Figure 4: STATCOM Control model

Here the current regulator predicts the voltage V2 that is the output voltage from the measurement of $\mathrm{V} 1$ and the transformer leakage reactance.

Major advantages of VSC based STATCOM over SVC are:

1) The support is provided to maintain reactive power by STATCOM even there is a decrease in terminal voltage.

2) Transient rating is higher in both capacitive and inductive regions.

3) For same rating of KVAR the size of SVC is larger than STATCOM.
4) The cost for constructing the STATCOM is lesser than $\mathrm{SVC}$ as there is no reactor or capacitor banks.

\section{Fuzzy Controller for STATCOM}

This Fuzzy Logic Controller is one of the most advanced approach which solves nonlinear problems in a system and provide controlling to the system. Here it is used in the STATCOM in its control loop. Here the fig shows the simple Fuzzy Logic Controller which consists of block called fuzzification which converts the binary input given to fuzzy, rule base block which gives the base knowledge, fuzzy inference and the block called defuzzification which converts the fuzzy output to binary. Here the error voltage and its derivative value is fed to the inputs of fuzzy controller.

The fuzzy controller for the STATCOM is designed by using the Mamdani type. The process of designing the controller involves the transforming of error crisp values to the linguistic variables through the fuzzification process. The inputs taken are the error voltage and the derivative of the error voltage in the sub block of the STATCOM controller. The basic block diagram is given in fig 5 .

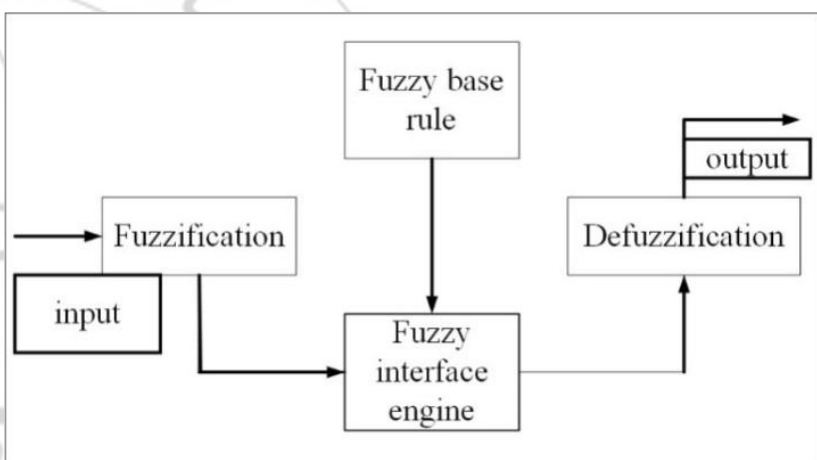

Figure 5: Basic fuzzy controller

The two inputs with seven linguistic terms forms 49 rules which are developed. The inputs and output are given a range from -1 to 1 in the membership function interface. Fig 6 shows the membership function for input 1 .

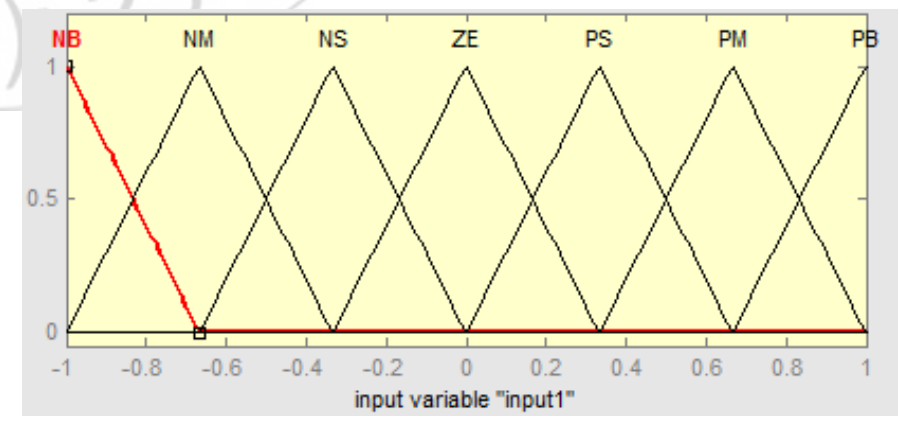

Figure 6: Membership function for input 1

\section{Simulation Results}

\section{A. Test system}

In this system the machine ratings used are machine 1 having $1000 \mathrm{MW}$ and machine 2 having $5000 \mathrm{MW}$ rating, the load is connected to the swing bus which has a rating of $5000 \mathrm{MW}$ and transformer connected across the both machines provide the $500 \mathrm{KV}$ voltage across the $700 \mathrm{KM}$ transmission line. 


\section{International Journal of Science and Research (IJSR) \\ ISSN (Online): 2319-7064 \\ Index Copernicus Value (2013): 6.14 | Impact Factor (2015): 6.391}

The fault connected across the line near the bus 1 is a triple line to ground fault and its transition timing is of $0.1 \mathrm{sec}$ from $1 \mathrm{sec}$ to $1.1 \mathrm{sec}$ where circuit breaker is connected to clear the connected fault. The facts device connected in the line is at midpoint of the line. The power rating of both the STATCOM and SVC is 200 MVar. The SVC, STATCOM and fuzzy controlled STATCOM are simulated for the same triple line to ground fault. The type of FACTS devices blocks used in this system are phasor type. The connected frequency of the system is $60 \mathrm{~Hz}$ and the devices used to compensate the reactive power and stabilize the system should also be set at the mentioned frequency. In Fig 4.1 the design of STATCOM device is shown which is connected to the system transmission line at mid-point range as the efficient location for the connection to better improve the system transient stability condition in voltage regulation mode of working.

The single diagram of the transmission system is provide in fig 8 .

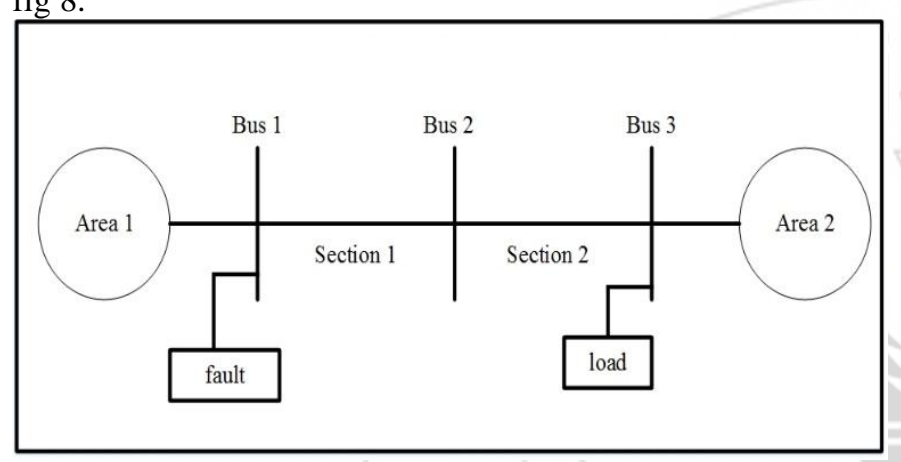

Figure 7: Single line model of two machine system

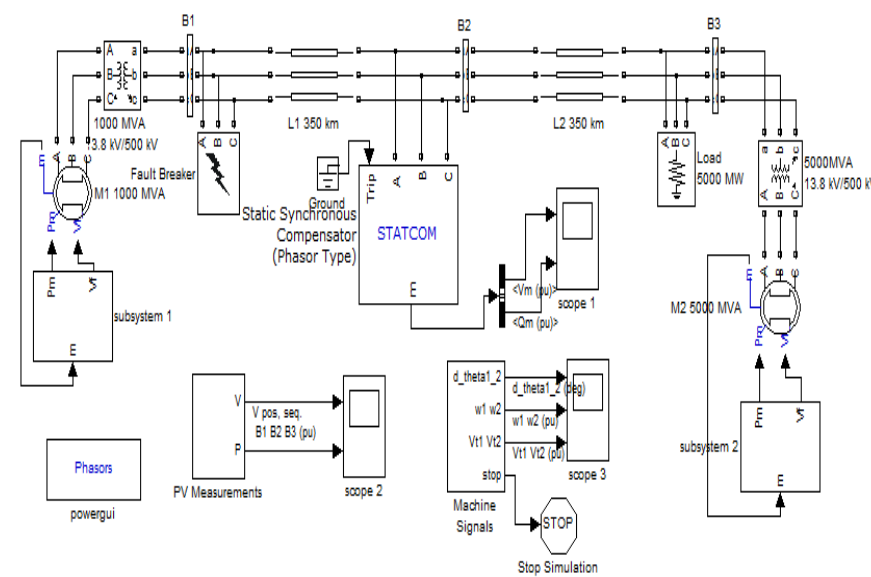

Figure 8: Simulink diagram of STACOM on two machine system

\section{B. The simulation results for conventional SVC}

At first the results produced by the SVC facts device is used in the simulation. In fig 10 the rotor angle deviation produced by the device is taken from the simulation as the fault is applied at the time of $1 \mathrm{sec}$ and the circuit breaker is applied at $1.1 \mathrm{sec}$ for $0.1 \mathrm{sec}$ transition time. The rotor angle deviation of the machines 1 and 2 are combined are subtracted using sum function in MATLAB. Here the fault is cleared at the time of $8 \mathrm{sec}$. At this time the systems present oscillations are damped and the transient stability of the system takes place from the instability.
The angular velocities w1 and w2 are calculated of the two generators provided in the system. When the SVC device is provided to improve the transient stability of the system the angular velocities are varying in both aspects. The plot shown in fig 11 is the graph of the angular velocities in per unit to time. The terminal voltages of both the generators Vt1 and $\mathrm{Vt} 2$ are plotted fig 12 across time in per units. Due to occurrence of the triple line to ground fault the terminal voltages are brought to stability using the SVC facts device.

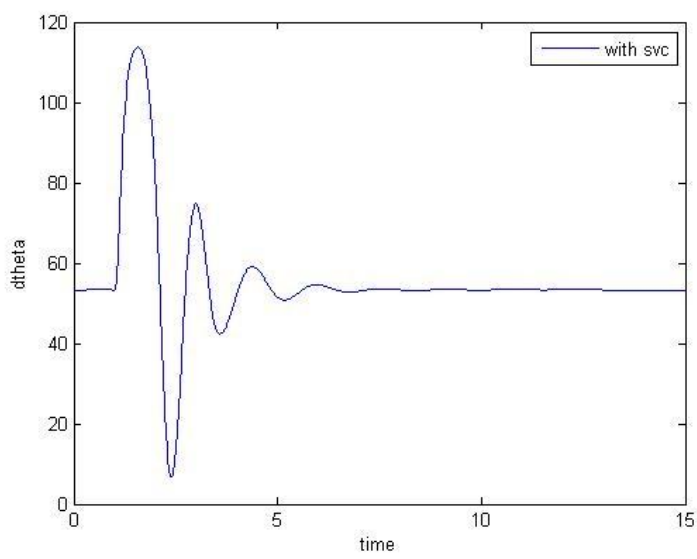

Figure 9: Rotor angle deviation with conventional SVC

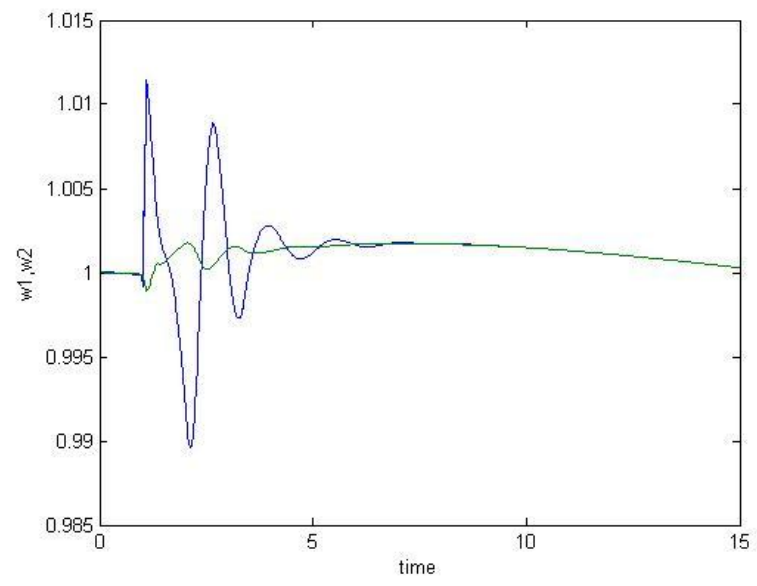

Figure 10: Angular velocity with conventional SVC

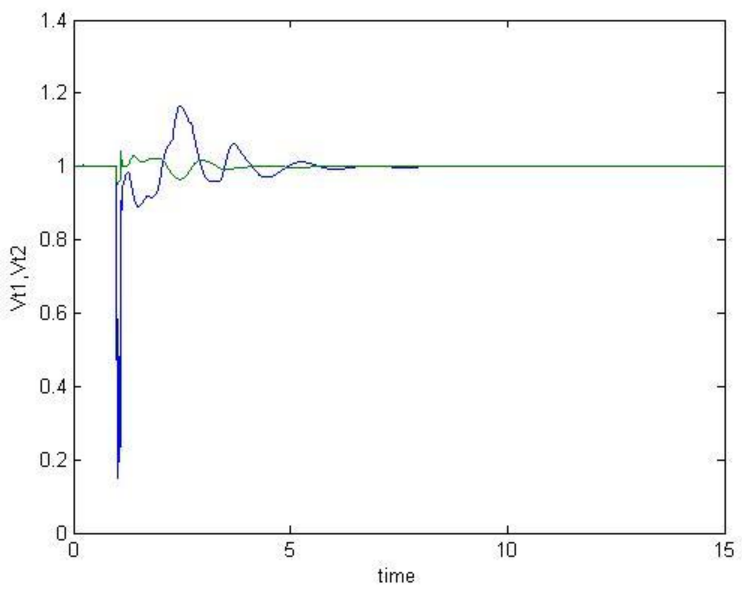

Figure 11: Terminal voltages with conventional SVC

\section{The simulation results for conventional STATCOM}

The rotor angle deviation produced by the device is taken from the simulation as the fault is applied at the time of $1 \mathrm{sec}$ 


\section{International Journal of Science and Research (IJSR) \\ ISSN (Online): 2319-7064}

Index Copernicus Value (2013): 6.14 | Impact Factor (2015): 6.391

and the circuit breaker is applied at $1.1 \mathrm{sec}$ for $0.1 \mathrm{sec}$ transition time. Here the fault is cleared at the time of 7.3 sec. The result of the signal is given in fig 13 where the amplitude of the peak overshoot if the rotor angle deviation is 109 degrees.

The angular velocities $w 1$ and $w 2$ are calculated of the two generators provided in the system. When the STATCOM device is provided to improve the transient stability of the system the angular velocities are varying in both aspects. The terminal voltages of both the generators $\mathrm{Vt} 1$ and $\mathrm{Vt} 2$ are plotted in fig 15 is a graph across time in per units. Due to occurrence of the triple line to ground fault the terminal voltages are brought to stability using the STATCOM facts device.

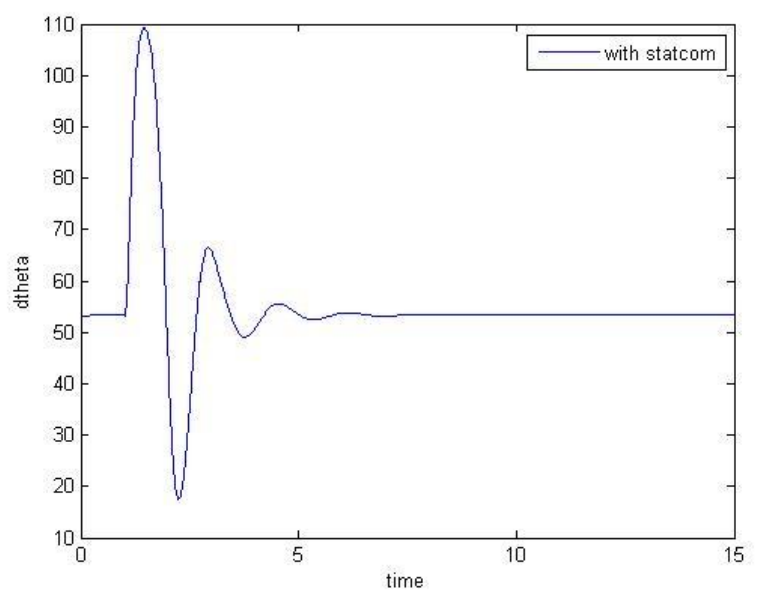

Figure 12: Rotor angle deviation with conventional STATCOM

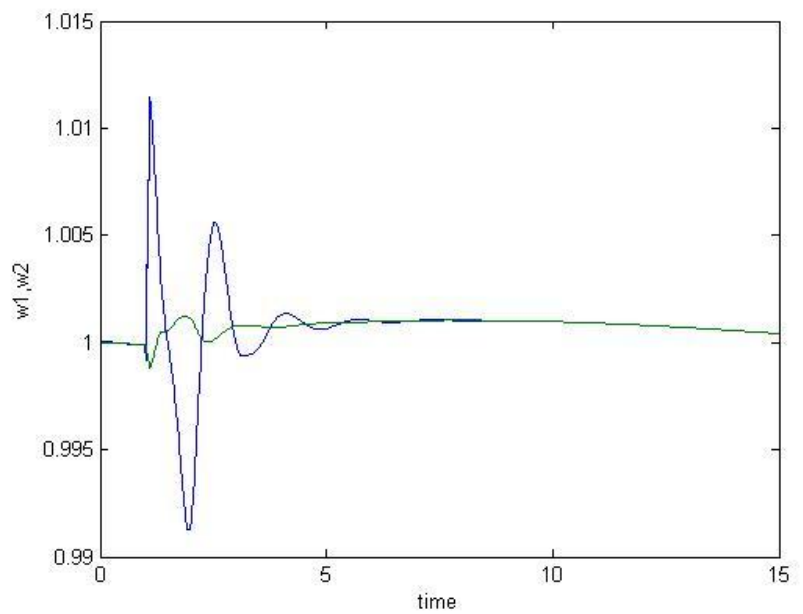

Figure 13: Angular speed with conventional STATCOM

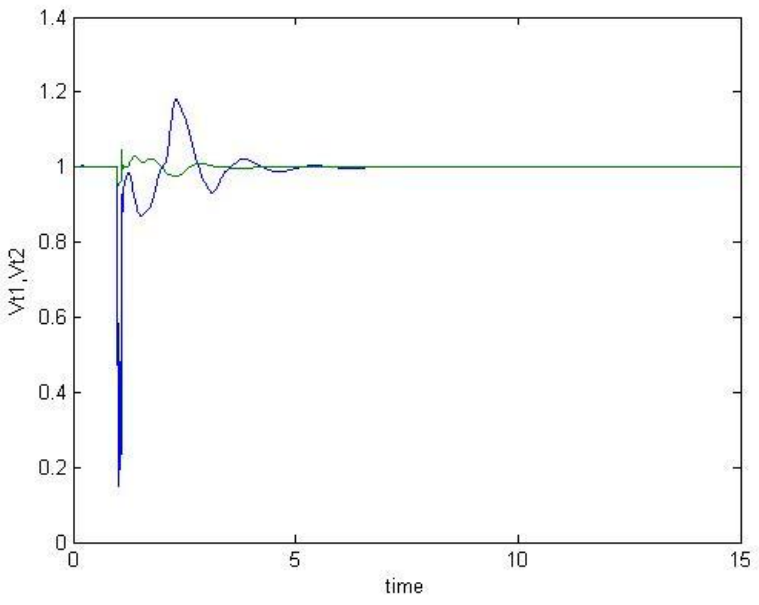

Figure 14: Terminal voltages with conventional STATCOM

D. The simulation results for Fuzzy controlled STATCOM

The rotor angle deviation produced by the device is taken from the simulation as the fault is applied at the time of $1 \mathrm{sec}$ and the circuit breaker is applied at $1.1 \mathrm{sec}$ for $0.1 \mathrm{sec}$ transition time. Here the fault is cleared at the time of 3.5 sec. The result of the signal is given in fig 16 where the amplitude of the peak overshoot if the rotor angle deviation is 85 degrees.

The angular velocities w1 and w2 are calculated of the two generators provided in the system. When the fuzzy controlled STATCOM device is provided to improve the transient stability of the system the angular velocities are varying in both aspects. The plot shown in fig 17 is the graph of the angular velocities in per unit to time.

The terminal voltages of both the generators $\mathrm{Vt} 1$ and $\mathrm{Vt} 2$ are plotted in fig 18 is a graph across time in per units. Due to occurrence of the triple line to ground fault the terminal voltages are brought to stability using the fuzzy controlled STATCOM facts device.

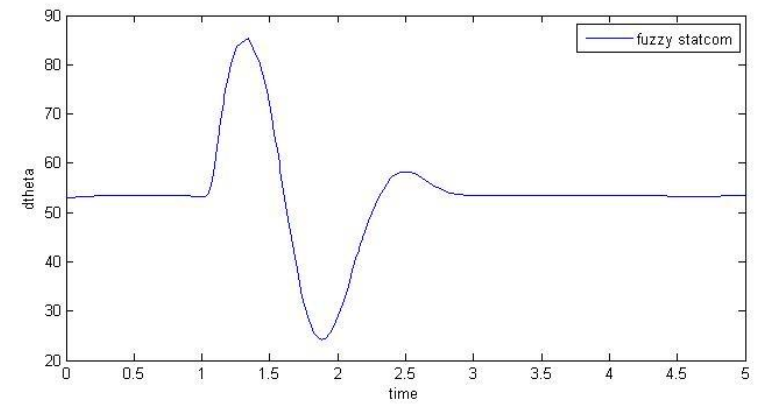

Figure 15: Rotor angle deviation with Fuzzy controlled STATCOM 


\section{International Journal of Science and Research (IJSR) \\ ISSN (Online): 2319-7064}

Index Copernicus Value (2013): 6.14 | Impact Factor (2015): 6.391

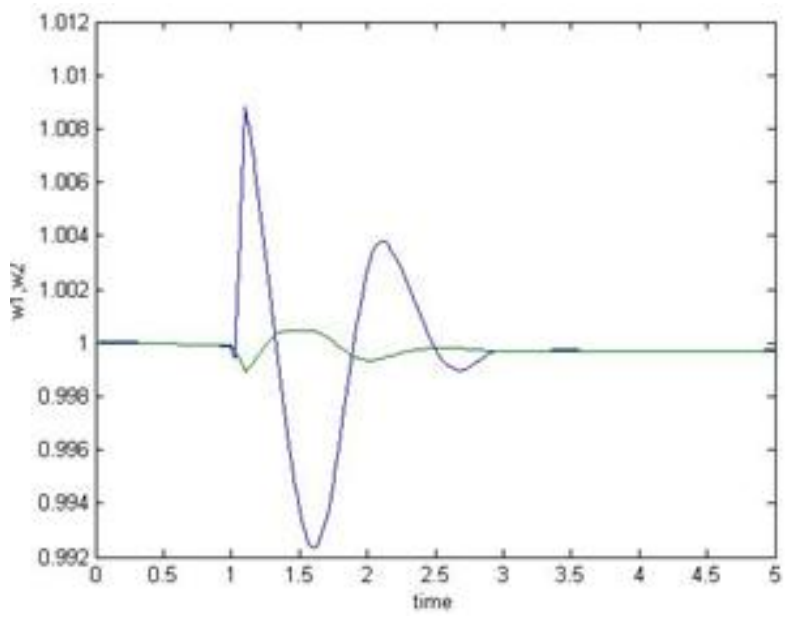

The fig 19 represents the results obtained by combining the plot graphs taken from the two different controller and one fuzzy controlled device and we can see that the fuzzy controlled device is more suitable for improving the transient stability. In table 2 the results of the peak overshoot and settling time is shown.

Table 1: Comparison of results

\begin{tabular}{|c|c|c|}
\hline & $\begin{array}{c}\text { dtheta (peak overshoot) } \\
\text { in degrees }\end{array}$ & $\begin{array}{c}\text { Settling time } \\
\text { in sec }\end{array}$ \\
\hline With SVC & 113.7 degrees & $8 \mathrm{sec}$ \\
\hline With STATCOM & 109 degrees & $7.3 \mathrm{sec}$ \\
\hline $\begin{array}{c}\text { With FUZZY controlled } \\
\text { STATCOM }\end{array}$ & 87 degrees & $3.5 \mathrm{sec}$ \\
\hline
\end{tabular}

Figure 16: Angular speed with Fuzzy controlled STATCOM

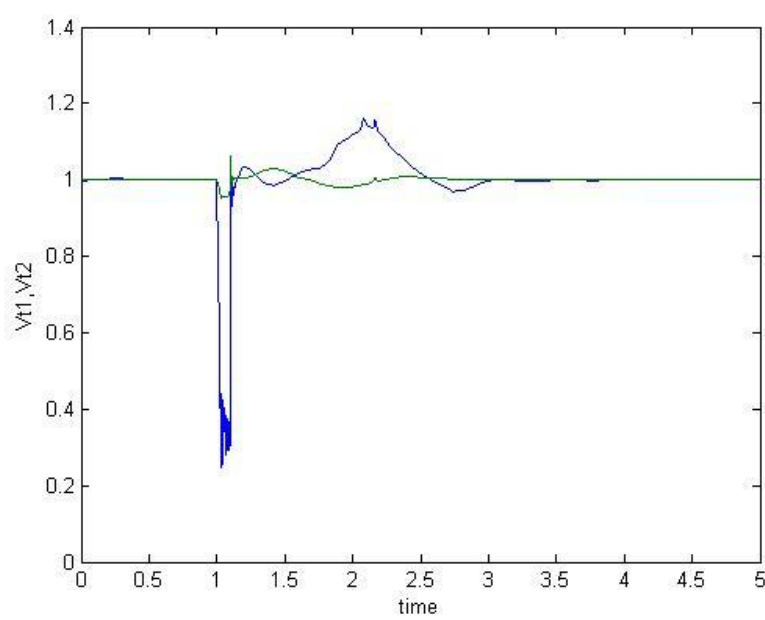

Figure 17: Terminal voltages with Fuzzy controlled STATCOM

\section{Result}

From the different plots of graphs shown in this thesis the combined comparison of the proposed FACTS devices are shown and the fuzzy controlled device which is a nonlinear calculating and controlling device gives better damping of the oscillations produced in the system by the faults due to environmental disturbances in the transmission lines or voltage sags.

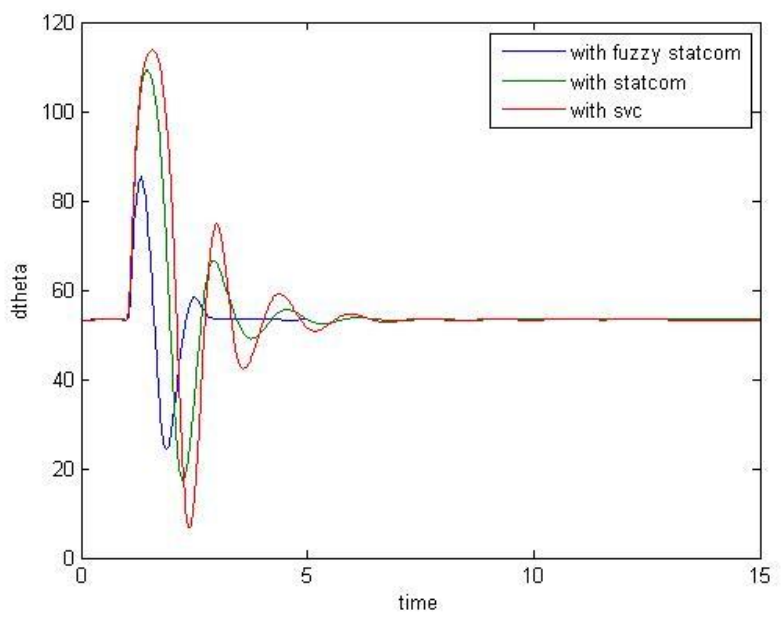

Figure 19: Comparison of Rotor angle deviation

\section{Conclusion}

In this paper at first transient stability improvement is carried out with the help of shunt FACTS devices like SVC and STATCOM where during comparison of both devices it was proved that STATCOM is better controller than SVC so the Fuzzy controlled STATCOM is designed to further improve the transient stability through fast damping of rotor angle deviation. The results obtained proved that Fuzzy controlled STATCOM is better controlling device than the conventional SVC and STATCOM.

\section{References}

[1] Kundur, P., 1993. "Power system stability and control", McGraw Hill New York.

[2] Hingorani and Gyungi. N.G., 2000, "Understanding FACTS devices" IEEE Press.

[3] Ajay Chaudhary and Ram AvtarJaswal, 2014. "Transient stability improvement of multi machine power system using static var compensator" Volume. 7, Issue 2, pp.109. 114.

[4] Ghahremani, E., Kamwa, I., 2013. "Joint improvement of system loadability and stability through a multi-stage planning of a UPFC with a PMU-based supplementary damping control" IEEE.

[5] Habibur Rahman and Fayzur Rahman, Md., Rashid, 2012. "Stability improvement of power system by using SVC with PID controller"International Journal of Emerging Technology and Advanced Engineering, Volume. 2, Issue 7, ISSN: 2250-2459.

[6] Manogna, K. and Lalitha, B., 2015. "Transient stability improvement in transmission system using SVC with PIFuzzy Logic hybrid control" IOSR Journal of Electrical and Electronics Engineering, Volume. 10, Issue 4 Ver. III, ISSN: 2320-3331.

[7] Mohammad Abdul Baseer, 2014. "Transient stability improvement of multi-machine power system using Fuzzy Controlled TCSC" IOSR Journal of Electrical and Electronics Engineering, Volume. 9, Issue 1, ISSN: 23203331.

[8] Murali, D., Rajaram, M. andReka, N., 2010., "Comparison of FACTS devices for power system stability 


\section{International Journal of Science and Research (IJSR) \\ ISSN (Online): 2319-7064}

Index Copernicus Value (2013): 6.14 | Impact Factor (2015): 6.391

enhancement", International Journal of Computer Applications, Volume. 8-No. 4.

[9] Nareshbabu, U. and Kiranmayi, R., 2014 "Modelling and simulation of STATCOM for compensation of reactive power by using PI with Fuzzy Logic Controller"IJREAT International Journal of Research in Engineering \& Advanced Technology, Volume. 2, Issue 2, ISSN: $2320-$ 8791.

[10]Ni Yixin and Mak Lai On, 1999. "Fuzzy logic damping controller for facts devices in interconnected power systems", IEEE.

\section{Author Profile}

B. Gopal Reddy was born in kadapa, Andhra Pradesh, India in 1992 and is currently pursuing B. Tech.-M. Tech. (dual degree) in Electrical and Electronics Engineering in Lovely Professional University, Phagwara, Punjab. And currently working on research for FACTS devices using advanced fuzzy techniques.

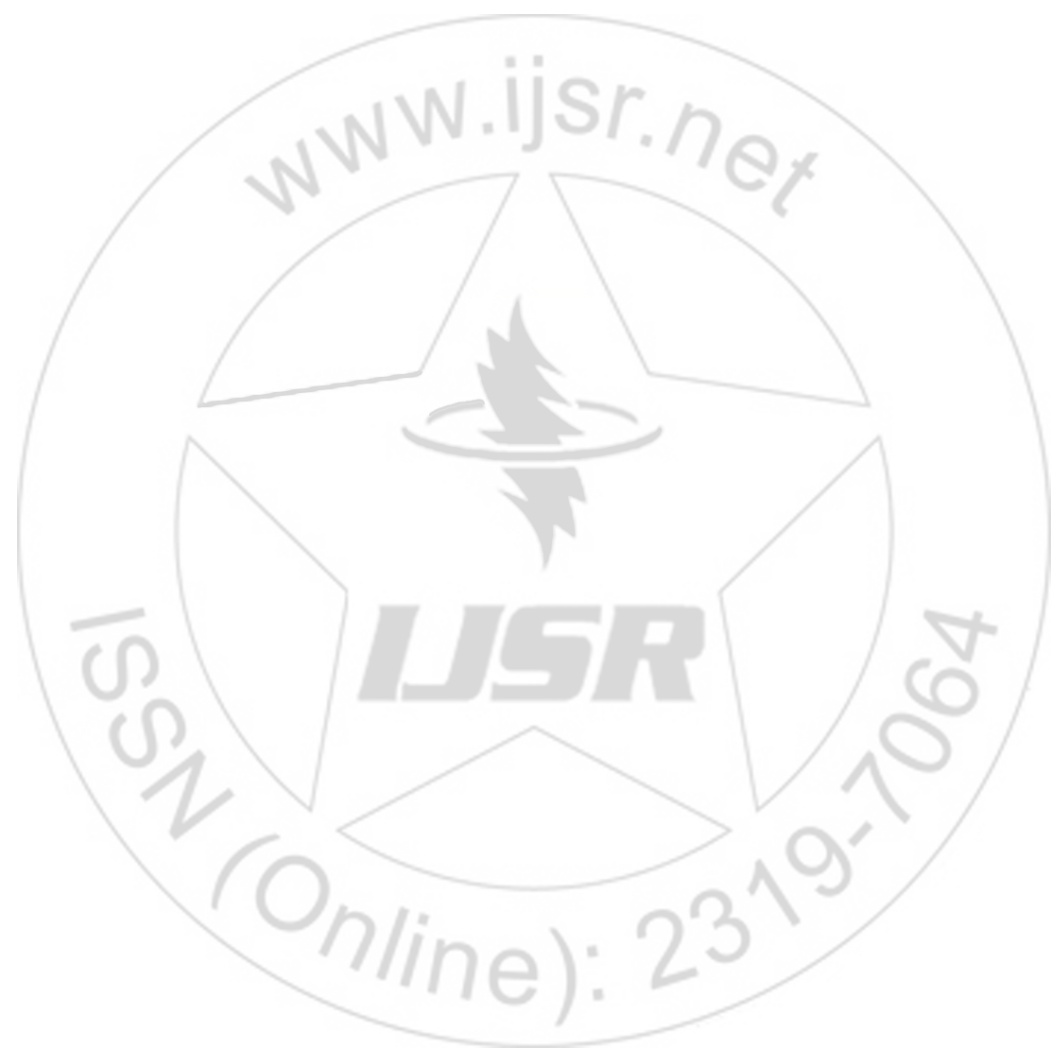

